\title{
Genetic characterization of dengue virus type 3 isolates in the State of Rio de Janeiro, 2001
}

M.P. Miagostovich,

F.B. dos Santos,

T.S. de Simone, E.V. Costa,

A.M.B. Filippis,

H.G. Schatzmayr and

R.M.R. Nogueira
Departamento de Virologia, Instituto O swaldo Cruz, Fundação O swaldo Cruz, Rio de Janeiro, RJ, Brasil

\section{Correspondence}

M.P. Miagostovich

Departamento de Virologia

Pavilhão Cardoso Fontes

Instituto O swaldo Cruz, FIOCRUZ

Avenida Brasil, 4365

21045-900 Rio de Janeiro, RJ

Brasil

Fax: + 55-021-598-4491

E-mail: marizepm@ioc.fiocruz.br

Research supported by CNPq (No. 40.0164/98-1), FAPERJ and Fundação $O$ swaldo Cruz. M.P. Miagostovich, H.G. Schatzmayr and R.M.R. Nogueira were supported by fellowships from CNPq.

Received November 26, 2001 Accepted June 20, 2002

\section{Abstract}

The genetic characterization of dengue virus type 3 (DEN-3) strains isolated from autochthonous cases in the State of Rio de Janeiro, Brazil, in 2001 is presented. Restriction site-specific (RSS)-PCR performed on 22 strains classified the Brazilian DEN-3 viruses as subtype C, a subtype that contains viruses from Sri Lanka, India, Africa and recent isolates from Central America. Nucleic acid sequencing (positions 278 to 2550) of one DEN-3 strain confirmed the origin of these strains, since genotype III - classified by sequencing and RSS-PCR subtype $\mathrm{C}$ are correlated. This genetic subtype has been associated with hemorrhagic dengue epidemics and the information provided here could be useful to implement appropriate prevention and control measures.

Dengue (DEN) viruses, which belong to the genus Flavivirus (Flaviviridae family), have four distinct antigenic serotypes (1 to 4) that cause a spectrum of disease ranging from asymptomatic, mild undifferentiated fever and classical dengue fever to severe disease named dengue hemorrhagic fever/dengue shock syndrome (DHF/DSS) $(1,2)$.

Dengue virus infections are endemic throughout tropical and subtropical regions of the world, being considered to be the most important reemerging disease in developing countries. High dengue virus activity in Central America in the late 70 s and 80 s led to the introduction of these viruses in Brazil, where they have been responsible for the occurrence of extensive dengue epidemics over the last fifteen years $(3,4)$. In 1986, after
DEN-1 virus introduction and extensive spreading, a National Network of Dengue Diagnosis able to perform routine laboratory confirmation of dengue infections was set up in the country (5). Since then, the Laboratory of Flaviviruses, Oswaldo Cruz Institute/ FIOCRUZ, has been carrying out an effective dengue surveillance program that includes the ongoing systematic collection and sample analysis of suspected cases. Through this program it was possible to detect the introduction of DEN-2 and DEN-3 viruses in the State of Rio de Janeiro in 1990 and 2000, respectively. In both cases, new serotypes were isolated from classical dengue fever during epidemic outbreaks when DEN-1 was the predominant serotype $(6,7)$.

Virologic surveillance systems not only 
allow the detection of the introduction of new serotypes but also the identification of distinct genotypes within each serotype, since genetic analysis has been providing information about dengue virus spread and has revealed important information related to disease transmission and severity (8).

Genome sequencing provides accurate characterization of strain differences but requires labor-intensive procedures. Recently, a new PCR-based approach has been used to rapidly subtype dengue viruses. The method consists of a single reverse transcriptasepolymerase chain reaction (RT-PCR) amplification using four primers that target regions spanning restriction site-specific polymorphic endonuclease (RSS-PCR) within the envelope gene (9).

Here, we present the genetic characterization by RSS-PCR and by partial genome sequencing of DEN-3 viral strains from autochthonous cases that occurred in the State of Rio de Janeiro, Brazil, in 2001 in order to understand their introduction.

The 22 DEN-3 viruses analyzed in the present study were obtained from the collection of the Laboratory of Flaviviruses, De-

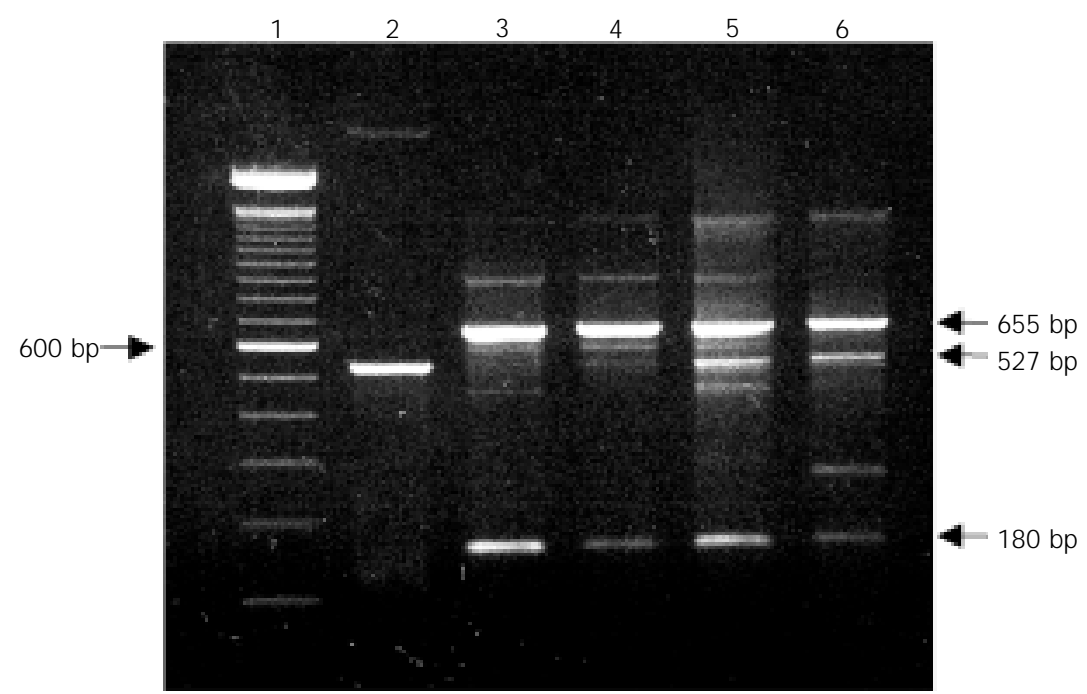

Figure 1. RSS-PCR patterns of DEN-3 viruses. Agarose gel electrophoresis of RSS-PCR products. Lane 1, 100-bp ladder (Gibco); lane 2, Indonesia 1976 (A2 pattern); lane 3, Thailand 1984 (B1 pattem); lane 4, Philippines 1956/H87 (B2 pattern); lane 5, Sri Lanka 1985 (C pattern); lane 6, Brazilian DEN-3 strain (68784). partment of Virology, Oswaldo Cruz Institute, FIOCRUZ. The strains were isolated from patient sera by inoculation into the Aedes albopictus $\mathrm{C} 6 / 36$ cell line and were identified by immunofluorescence using type-specific monoclonal antibodies (10).

Viral RNA was extracted from the culture supernatant of infected cells using the QIAamp Viral Mini kit (Qiagen, Inc., Valencia, CA, USA) according to the manufacturer's protocol.

RSS-PCR for DEN-3 viruses was performed as previously described (9) and yielded three reproducible patterns identified as A, B and C. These patterns are consistent with the genotypes previously described by sequencing and are as follows: RSS-PCR type A and B consisting of Indonesian, Philippine and Thailand strains from different decades, RSS-PCR type C represented by strains from Sri Lanka (19811985) and recent isolates from Central America, e.g., Nicaragua (1995-1998), Guatemala (1997) and El Salvador (1998). According to the different RSS-PCR patterns previously described (10), all 22 DEN-3 Brazilian strains were classified as type $\mathrm{C}$, since RSS-PCR produced bands of 655, 527 and 180 bp in size (Figure 1). Extra bands could be explained by an excess of template, although a band of $\sim 450 \mathrm{bp}$ in the subtype $\mathrm{C}$ RSS-PCR pattern was previously described as sample-to-sample variation (10).

Nucleotides corresponding to positions 278 to 2550 in the DEN-3 genome encoding the $\mathrm{prM} / \mathrm{M}$ and envelope proteins were amplified using RT-PCR for direct sequencing (11). After electrophoresis on $1 \%$ agarose gel, DNA fragments were excised and purified using the QIAquick ${ }^{\mathrm{TM}}$ Gel Extraction kit $\left(\right.$ Qiagen $\left.{ }^{\circledR}\right)$. Nucleic acid sequencing was performed with an automated Applied Biosystem 310 DNA sequencer using the BigDye $^{\text {TM }}$ Terminator Cycle Sequencing kit (PE Applied Biosystems, Foster City, CA, USA) using primers described previously (11). The sequencing cycle parameters used 
were as described in the manufacturer's protocol and the nucleic acid sequence was determined (GenBank, accession number AY038605).

Parsimony analysis using PAUP (D. Sworfford, Champaign, IL, USA) of the Brazilian DEN-3 strain and DEN-3 strains obtained from GenBank representing the four genotypes previously described (11) generated a phylogram that assigned the Brazilian DEN-3 strain to genotype III, which includes viruses from Sri Lanka, India and Africa (Figure 2). Genotype III corresponds to RSSPCR subtype $C$ as previously described (10).

The similarity of the Brazilian DEN-3 strain to others represented by the same genotype III ranged from 96 to $98 \%$ and from 98 to $99 \%$ for nucleic acid sequence and deduced amino acid sequence, respectively. The comparison of the Brazilian DEN-3 virus with recent strains isolated in Guatemala showed a total of 14 nucleic acid changes, with one resulting in an amino acid change from histidine to arginine (data not shown).

After an absence of 16 years, DEN-3 reappeared in the Americas, first in Nicaragua and later in Panama, Costa Rica, El Salvador, Guatemala, Honduras and Mexico $(12,13)$.

In Brazil, DEN-3 virus was isolated in São Paulo in 1998 from an imported case and since then no more cases were detected in that region, showing no DEN-3 virus transmission (14). After two years, DEN-3 virus was introduced into the State of Rio de Janeiro, being the first autochthonous virus isolated in the municipality of Nova Iguaçu from a 40-year-old woman who presented classical dengue fever and who fully recovered from the illness (7). This first isolation in December 2000 was followed by the confirmation of 91 cases in three different municipalities in the state (Secretary of Health of Rio de Janeiro).

DEN-3 virus was detected in an ongoing Surveillance Program carried out in an endemic municipality that has reported DEN-1 and DEN-2 cases practically throughout the year 2000. The introduction of a new serotype in a region where the population has been repeatedly exposed to dengue infections may significantly increase the probability of developing DHF/DSS.

Genetic characterization by RSS-PCR and phylogenetic analysis showed that Brazilian

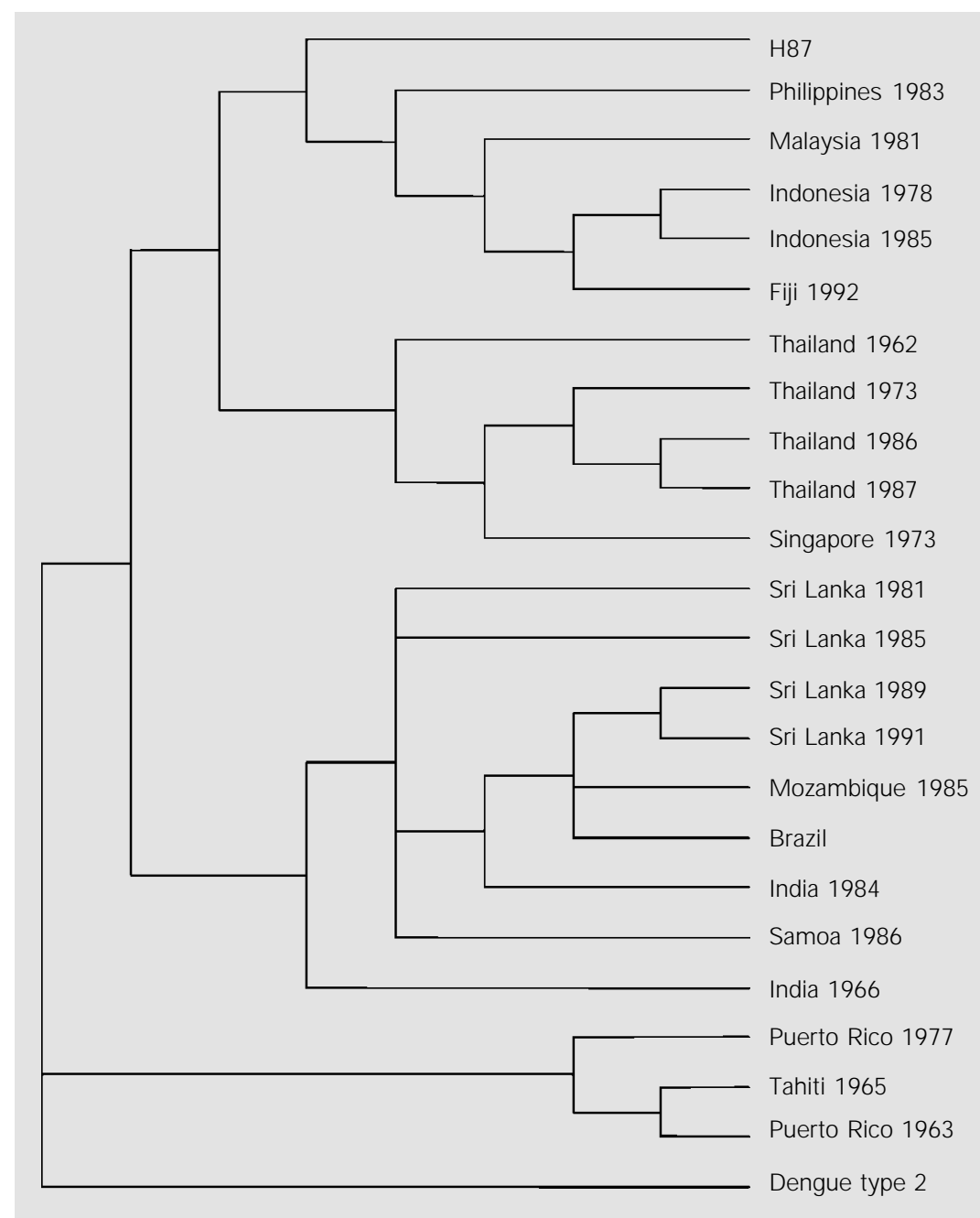

Figure 2. Phylogram generated by parsimony analysis of nucleic acid sequences from the $\mathrm{prM} / \mathrm{M}$ and envelope genes of 22 DEN-3 viruses obtained from GenBank, one Brazilian DEN-3 strain and one DEN-2 (GenBank) used as outgroup. Accession number: L11423 (Philippines 1956/H87); L11432 (Philippines 1983); L11427 (Malaysia 1981); L11426 (Indonesia 1978); L11428 (Indonesia 1985); L11422 (Fiji 1992); L11440 (Thailand 1962); L11620 (Thailand 1973); L11441 (Thailand 1986); L11442 (Thailand 1987); L11431 (Sri Lanka 1981); L11436 (Sri Lanka 1985); L11437 (Sri Lanka 1989); L11438 (Sri Lanka 1991); L11430 (Mozambique 1985); AY038605 (Brazil 2000); L11424 (India 1984); L11435 (Samoa 1986); L11434 (Puerto Rico 1977); L11439 (Tahiti 1965); L11433 (Puerto Rico 1963); AF489932 (Dengue type 2). The Singapore 1973 and India 1966 nucleotide sequences were kindly provided by Dr. Robert Lanciotti (CDC). 
DEN-3 has the same origin, described as subtype $\mathrm{C}$ by RSS-PCR or genotype III by sequencing. This subtype/genotype has been associated with major DHF epidemics in Sri Lanka and India and with DHF cases and deaths in Mexico and in Central American countries (13).

The rapid results obtained by RSS-PCR show that this alternative method, designed to be rapid and low cost, could be useful in virological surveillance laboratories, mainly due to an obvious need to characterize dengue genotypes before a major outbreak occurs. The high similarity obtained by nucleotide and deduced amino acid sequence between DEN-3 genotype III strains and American strains in particular indicates the probable origin of the virus circulating in the state.

The risk of the introduction of new serotypes in Brazil has been stressed and expected mainly due to the circulation of the four serotypes in the bordering countries. DEN-3 introduction in the State of Rio de Janeiro repeats what was observed for
DEN-1 and DEN-2 viruses in 1986 and 1990, respectively, since the state was again the port of entry for a new serotype into the country (3). Considering the large human contingent circulating through the international airport and highways of the state, a rapid spread of this new serotype to other states is expected, possibly resulting in extensive epidemics, mainly due to the high population susceptibility and to the difficulties concerning mosquito control.

The genetic analysis presented here may serve as an alert to the potential severity of epidemics caused by the circulating DEN-3 strain.

\section{Acknowledgments}

The authors wish to thank Dr. Eva Harris for providing the RSS-PCR patterns, Dr. Robert Lanciotti for generating the phylogram, and Dr. Ary Carvalho de Miranda, Vice-President, FIOCRUZ, for encouragement and support.

\section{References}

1. Westaway EG, Brinton MA, Gaidamovich SY, Horzinek MC, Igarashi A, Kaariainen L, Lvov DK, Porterfield J E, Russell PK \& Trent DW (1985). Flaviviridae. Intervirology, 24: 183-192.

2. WHO/World Health Organization (1997). Dengue Haemorrhagic Fever: Diagnosis, Treatment and Control. WHO, Geneva, Switzerland.

3. Nogueira RMR, Miagostovich MP, Schatzmayr HG, dos Santos FB, Araújo ESM, Filippis AMB, Souza RV, Zagne SMO, Nicolai C, Baran M \& Filho GT (1999). Dengue in the State of Rio de J aneiro, Brazil, 1986-1998. Memórias do Instituto Oswaldo Cruz, 94: 297-304.

4. Figueiredo LTM (2000). The Brazilian flaviviruses. Microbes and Infection, 2: 16431649.

5. Schatzmayr HG, Nogueira RMR \& Miagostovich MP (1996). Dengue in Brazil: laboratory aspects and perspectives. Virus Reviews and Research, 1: 17-21.

6. Nogueira RMR, Miagostovich MP, Lampe
E \& Schatzmayr HG (1990). Isolation of dengue virus type 2 in Rio de Janeiro. Memórias do Instituto Oswaldo Cruz, 85: 253.

7. Nogueira RMR, Miagostovich MP, Filippis AMB, Pereira MAS \& Schatzmayr HG (2001). Dengue virus type 3 in Rio de J aneiro, Brazil. Memórias do Instituto Oswaldo Cruz, 96: 925-926.

8. Rico-Hesse R, Harrison LM, Alba Salas R, Tovar D, Nisalak A, Ramos C, Boshell J, De Mesa MTR, Nogueira RMR \& Travassos da Rosa A (1997). Origins of dengue type 2 viruses associated with increased pathogenicity in the Americas. Virology, 230: 244-251.

9. Harris E, Sandoval E, Johnson M, XetMull AM \& Riley LW (1999). Rapid subtyping of dengue viruses by restriction site-specific (RSS)-PCR. Virology, 253: 86-95.

10. Gubler DJ , Kuno G, Sather G, Velez M \& Oliver A (1984). Use of mosquito cell cultures and specific monoclonal antibodies in surveillance for dengue viruses. American J oumal of Tropical Medicine and Hygiene, 33: 153-165.

11. Lanciotti RS, Lewis J G, Gubler DJ \& Trent DW (1994). Molecular evolution and epidemiology of dengue-3 viruses. Journal of General Virology, 75: 65-75.

12. Anonymous (1995). Dengue 3 in Central America. Dengue Surveillance. Summary. Dengue Branch, Division of Vector-Bome Infectious Diseases, San J uan, Puerto Rico, Vol. 70, 4

13. Figueroa $R \&$ Ramos C (2000). Dengue virus (serotype 3 ) circulation in endemic countries and its reappearance in America. Archives of Medical Research, 31: 429-430.

14. Rocco IM, Kavakama BB \& Santos CLS (2001). First isolation of dengue 3 in Brazil from an imported case. Revista do Instituto de Medicina Tropical de São Paulo, 43: 55-57. 